\section{Arte e linguagem}

Coletânea. Petrópolis, Editora Vozes, 1973. $141 \mathrm{p}$.

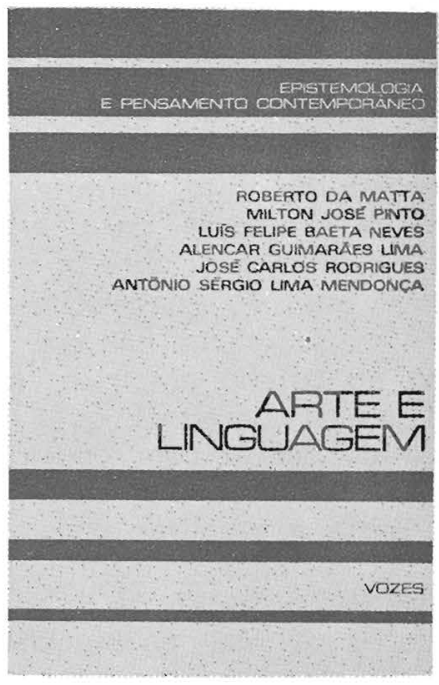

A primeira impressão deixada pela leitura da coletânea Arte e linguagem é a de uma inesperada heterogeneidade que não se explica pela variedade de objetos analisada nos seis ensaios do livro: contos, romances, fotonovelas, história em quadrinhos, peça teatral. Tal heterogeneidade resulta sobretudo da diversidade teórica materializada nos textos (além de diferenças no grau de elaboração, na fecundidade e, simplesmente, na qualidade destes). Ela só será inesperada, entretanto, para quem supuser que a análise do discurso narrativo - rubrica que define a coletânea - consiste em uma teoria. A análise do discurso, efeito mais ou menos direto da revolu. ção "estruturalista" nas ciências sociais, é antes um domínio possível de objetos, aberto pela confluência recente de disciplinas como a antropologia, a lingüística e a psicanálise. A unificação teórica deste domínio, bem como a constituição de uma metodologia integrada, pertencem ainda a um futuro problemático: em torno do objeto discurso, idealmente situado num nível de abstração tal que permitisse a sistematização e relativa padronização de tratamento de suas manifestações regionais (discurso artístico, político, mítico, científico), persiste uma polêmica onde pesam as tradições de cada disciplina envolvida, seus problemas específicos e seus métodos. De qualquer modo, a possibilidade de pensar objetos como - discurso artístico ou a cultura de massa através do instrumental da antropologia e da lingüistica está aberta, e caminha resolutamente para o abandono de alguns impasses já antigos nesta área: apesar das diferenças teóricas no campo da análise do discurso, fica patente uma recusa geral do sociologismo ingênuo, das divisões pragmáticas entre os tipos de discurso e do isolamento tranquiilo de cada ciência social. A alternativa que se busca pode ser resumida, em seus traços mais gerais, assim: trata-se de refinar a correlação entre as formações "superestruturais" e sua base social, por meio de um estudo dos mecanismos específicos das instâncias discursivas, que encontre a dimensão simbólica como objeto teórico irredutível. Nessa busca se cruzam todas as ciências que vêm obtendo resultados satisfatórios nas áreas do simbólico de sua "competência", como as apontadas acima (antropologia, lingüística, psicanálise). E seu entrecruzamento, definindo a análise do discurso, coloca a seguinte ordem de questões, especialmente para o caso dos objetos tratados pela coletânea da Vozes: o estudo das relações entre arte e linguagem antecede epistemologicamente o estudo das relaçṍes entre arte e sociedade, o que não significa abso. lutamente uma incompatibilidade entre as questões, que, de resto, são complementares.

Mas, vejamos como os autores de Arte e linguagem desenvolvem seus temas. O primeiro ensaio Edgar Allan Poe, o 'Bricoleur': um exercício em análise simbólica é assinado por Roberto Da Matta. O autor é o nome mais conhecido dentre os que compõem a coletânea: é antropólogo, diretor do Departamento de Antropologia do Museu Nacional do Rio de Janeiro, possuindo vários trabalhos publicados em livros e revistas especializadas, no Brasil e no exterior. Seu ensaio, republicado aqui neste livro, data de 1965, e é, como escreve o apresentador da coletânea, "uma das primeiras tentativas brasileiras de análise estrutural exercida por um antropólogo so- cial e usando o acervo conceitual de sua disciplina - no sentido lévi-straussiano do termo, aplicada a um texto de ficção". Exercício brilhante e pioneiro, exemplifica excelentemente o potencial da análise estrutural lévi-straussiana e a importância da antropologia para a compreensão da literatura e dos fenômenos simbólicos em geral. Ele demonstra ainda como - "método" de Lévi-Strauss não se reduz a um receituário formal, mas que exige, ao contrário, o uso de "uma imaginação altamente estimulada", no dizer de Poe, citado em epígrafe. Registre-se, além disso, a coragem de Da Matta em sair de seu domínio acadêmico - passo que continuaria dando em suas obras, pois seu último livro (Ensaios de antropologia estrutural, publicado recentemente pela Vozes) retoma a obra de Poe e traz um estudo sobre o carnaval.

Da Matta apóia-se na categoria de bricolage (Lévi-Strauss) que, qualificando o modo de operação do "pensamento selvagem", é igualmente útil para a compreensão do discurso artístico, que também opera com um repertório limitado de signos (por razões histórico-sociais), reorganizando-o continuamente segundo suas necessidades de expressão. $\mathrm{O}$ artista é um bricoleur porque não cria novos instrumentos de acordo com as situações (como faz o cientista), mas que se apropria de fragmentos do discurso da comunidade e da tradição artística, deslocando seu significado, utilizandoos para outra coisa. Poe, para Da Matta, é o bricoleur por excelência. Seria mesmo um antropó logo estruturalista avan la lettre, na medida em que seus escritos denotam uma preocupação experimental, uma tentativa de construir modelos "cuja simplicidado e possibilidade de manipulação lançasse alguma luz em áreas obscuras e de difícil conceptualização da vida humana". Não deixa de ser curioso observar um antropólogo chamar seu "objeto" de antropólogo - lembremos, entretanto, que Lévi-Strauss qualifica suas Mythologiques como sendo um mita sobre a mitologia; e que, para ele, a bricolage é o sujeito e o objeto do discurso da antropologia. 
O conto "O Gato Preto" surge como adequado ao exercício estrutural de Da Matta por sua proximidade com o mito: tematiza as relações entre os sexos e entre o homem e os animais - problemas caros ao antropólogo - e se caracteriza por uma harmonia e concisão semelhantes à do mito. Ele é ainda o tipo de narrativa "translingüística", isto é, que não perde seu sentido quando traduzida (exatamente como o mito). Pode-se objetar aqui que essa proximidade com o mito, se facilita o emprego do instrumental antropológico e tem importante valor exploratório, não permite que se possa avaliar em toda a sua extensão a aplicabilidade do método estrutural à literatura. O problema fundamental da Poética - a relação entre som e sentido, conforme Jakobson - não aparece; e nos remetemos, como exemplo, aos poemas do próprio Poe.

A demonstração do autor inicia-se pela descrição dos poucos elementos presentes no conto de Poe; a seguir, estudam-se as combinações dentro desse repertório que permitem a emergência das mensagens, É-nos apresentada a máquina da narrativa numa perspectiva sincrônica que dá igualmente conta das mudanças sucessivas na posição dos elementos. Recortadas as dimensões organizadoras do "Gato Preto", da Matta analisa a posição dos personagens dentro dessas dimensões e as $\mathrm{fi}$ guras que ocupam o papel de mediação entre elass, permitindo sua ligação. A partir daí, torna-se inteligível o sentido do conto. Ápesar de seu caráter de esboço, não é difícil concordar com Da Matta quando ele diz, na introdução a seu ensaio, que decidiu republicálo porque sua análise "permanece de pé, quando comparada a certas tentativas de aplicação do método estrutural (seja ele de LéviStrauss, Propp ou Barthes) à análise em literatura". Gostaríamos apenas de observar que a categoria bricolage pode ser substituída com vantagem, no artigo de Da Matta, pelo conceito de inconsciente, fundamental na obra de Lévi-Strauss e mais explicativo que a primeira:

Mais marcadamente teórico que - primeiro, o segundo ensaio Literatura: símbolo e mito - es- crito por Milton José Pinto, retoma a problemática da teoria da interpretação semântica dos discursos, à qual se vem dedicando, "procurando mostrar que toda leitura estrutural, em qualquer nível que se coloque, é sempre uma interpretação hipotética a partir de um contexto de referência, que não tem o caráter ontológico de objetividade que Ihe empresta, por exemplo, Claude Lévi-Strauss" (L. F. Baeta Neves, apresentador e organizador da coletânea). Partindo de uma análise da novela "A hora e a vez de Augusto Matraga", de Guimarães Rosa, o autor propõe-se a mostrar como "determinadas estruturas lógicas a priori (armadura) são preenchidas num contexto cultural dado por determinados valores semânticos redundantes (código), gerando uma série de mensagens articuladas entre si e que se imbricam na linearidade aparente do discurso". Esses conceitos são originalmente lévi-straussianos, mas $M$. J. Pinto divergirá, em sua interpretação, de Lévi-Strauss. Roland Barthes (especialmente por sua reflexões sobre o nível conotativo do discurso) e o semanticista A.J. Greimas - responsável pela elaboração de um método de análise semântica fundado em Hjelmslev, Propp e, reinterpretado, LéviStrauss - são as referências principais do texto. Este termina com uma tentativa de repensar a tipologia dos discursos esboçada por Lévi-Strauss no Pensamento selvagem; a partir da identificação de dois níveis de leitura dos discursos (denotativo e conotativo), $M$. $J$. Pinto situa a literatura, especificada segundo os gêneros literários, no interior de um conjunto de discursos (mito, ciência, jogo, rito) diferenciado internamente segundo a relação estabelecida por cada tipo de discurso entre os dois níveis de estruturação citados. Observe-se que a problemática do "pensamento selvagem" e da bricolage, presente no artigo de Da Matta, vai ser retomada aqui, em outras bases.

O problema central de $M$. J. Pinto consiste em distinguir duas estruturas no interior do discurso narrativo: uma superificial, icônica, dominada pelo princípio da verossimilhança que, centrada no sujeito empírico da narrativa, se estabelece na relação entre esse sujeito e o mundo empírico; é ela que fornece $o$ contexto cultural para leitura, ao apontar para um referente (real ou imaginário). Essa estrutura denotativa, em si, permitirá apenas uma leitura descritiva que explicite o contexto. Já a outra estrutura discursiva, da ordem do mito, permite dar conta da conotação, da ambigüidade constitutiva da obra de arte. Trata-se aqui do estabelecimento de um metacontexto, não mais situado no sujeito empírico, mas num sujeito conceitual, que, deixando de operar com oposições locais, denotativamente identificáveis, passa a atualizar oposições míticas, cosmológico-metafísicas. O nível da conotação, ou da enunciação (e não mais do enunciado, como na primeira estrutura) não pode ser objeto de uma descrição objetiva, ele exige uma interpretação. Caberá ao analista articular dialeticamente as duas estruturas. É esta a hipótese que Milton José Pinto procura ilustrar através da análise da novela de Guimarães Rosa. Não nos arriscamos a avaliar tal hipótese; seria melhor esperar desenvolvimentos posteriores por parte do autor. De qualquer modo, pareceu-nos levar a contradições acentuadas quanto às tendências dominantes na análise do discurso (Lévi-Strauss, Lacan etc. ); e o endosso das posições teóricas da Nova Crítica francesa pode significar uma regressão da análise literária a soluções préestruturalistas.

"Economia e sociedade em Bongo-Bongo" é um interessante exercício antropológico (anteriormente publicado na revista Cadernos de Jornalismo e Comunicação) de autoria de Luiz Felipe Baeta Neves sobre um dos mais antigos e resistentes exemplares da cultura de massa: a história em quadrinhos Os sobrinhos do Capitão. Trata-se de uma descrição etnográfica do universo da história (a ilha de Bongo-Bongo, seus habitantes etc. ), e de uma análise da estrutura familiar que liga os personagens centrais da série, com suas práticas econômicas, seus sistema de poder e sua distribuição de papéis sociais. O autor, evi- 
tando especulações antropológicas sobre seu material, se atém a uma explicitação do que é dado se ver pela história: e, fazendo isso, vai sublinhar a significativa ausência de informações que refinam uma comunidade verossímil - as relações de parentesco são ambíguas e imprecisas; a subsistência econômica dos habitantes da ilha é inexplicável; a historicidade é radicalmente abolida. As únicas dimensões enfatizadas pela narrativa consistem no que 0 autor chamou de "sistemas de alianças de ação/retaliação" entre os personagens, e na distribuição dos papéis sciciais dentro da estranha família dos "Sobrinhos do Capitão", dado que esias dimensões são fundainentais para o desenrolar das situações centrais da história: os "Sobrinhos do Capitão" são a his"sória dos intermináveis conflitos entre grupos de aliança no seio da diminuta comunidade de BongoBongo, a qual se perpetua fora do tempo num equilíbrio instável mas sólido, mantido pela figura catalizadora de Dona Chucruts, a Mamãe autoritária e bonachona. Como descrição preliminar, a análise de L. F. Baeta Neves é instigante; abre caminho para um estudo mais detalhado do material, bem como deixa ver a possibilidade de tratamento análogo de outros exemplares de história em quadrinhos e da produção da cultura de massa em geral. Indique-se apenas a ausência de uma abordagem que envolva os aspectos visuais do material, uma análise da linguagem gráfica do texto - mas isto é outra questão, que pede outros instrumentos.

O artigo de Alencar Guimarães Lima: "O pecado de João Agonia: vigência e duplicação do símbolo" trata de uma peça teatral do autor português contemporâneo Bernardo Santareno. Como indica o título do ensaio, efetua-se aqui o estudo da simbologia empregada pelo dramaturgo, suas raízes na tradição popular, e o modo pelo qual a mensagem básica da peça se desdobra em símbolos redun. dantes; que a análise revela exprimirem a mesma relação em registros diferentes. O levantamento dos motivos recorrentes na obra de Bernardo Santareno permitirá a explicitação do universo simbó- lico do autor, sua carga mítica e as oposições cosmológicas que manipula. Através dessa análise em profundidade, o que se depreende do texto de Guimarães Lima é a vigência de vários níveis de interpretação na obra de arte. Essa questão: a polissemia do discurso artístico, sua ambigüidade essencial, a dominância da conotação na comunicação artística etc. é muito mais antiga que o estruturalismo ou a análise do discur. so; ela vai aparecer em pelo me. nos metade dos ensaios de Arie e linguagem, mais ou menos elaborada, em posição secundária ou principal - mas esse problema comum receberá sempre soluções diferentes. Dentro dessa diversidade talvez se possa aproximar o ensaio de Guimarães Lima com o de Milton José Pinto, na colocação do problema e tentativa de solução.

"Fotonovela: decomposição e recomposição" ensaio de José Carlos Rodrigues reconstitui os "padrões-modelo" que, socialmente motivados, geram os produtos da indústria cultural. Efetua-se primeiramente uma análise imanente da narrativa de alguns textos de fôtonovelas; decompondo-se esses textos segundo o modelo de LéviStrauss para a análise dos mitos chegar-se-á então ao estabelecimento de feixes de oposições semânticas que subjazem aos textos. Construído o quadro de relações, decompostas as mensagens, torna-se então possível entender a mensagem da fotonovela, seu sentido geral - em outros termos, a ideologia que veicula. Aparece nesse ensaio claramente a exigência imposta pela análise do discurso: a abordagem "imanente" precede a abordagem "transcendente", ou seja, é preciso construir o objeto discursivo em sua especificidade para depois articulá-lo a outros objetos, discursivos ou não. A função social da fotonovela, por mais diretamente constitutiva que seja quanto a esta, só pode ser encontrada em toda a sua significação se se construir o objeto fotonovela - e não tomálo como dado.

Finalmente, temos Antônio Sérgio Mendonça assinando "Comunicação e linguagem", anteriormente publicado em três partes.
Trabalhando sobre D. Casmurro, - autor utiliza um instrumental cuja origem lingüística foi reelaborada - e mesmo invertida pela obra do psicanalista Jacques Lacan. Os problemas que se debatem no texto giram em torno da constituição de uma teoria do simbólico, baseada na postulação dos planos real, simbólico e imagináíio da linguagem (Lacan). As categorias de denotação e conotação são retomadas e diferenciadas internamente segundo a lógica que rege a relação entre os eixos sintagmático e paradigmático do discurso. Preocupado ainda com a diferenciação entre texto literário e ideologia, a inflexão teórica do texto de A.S. Mendonça coloca-o em polêmica virtual com o ensaio de Milton José Pinto presente nesta mesma coletânea. É preciso avisar que o ensaio de Antônio Sérgio Mendonça não é de fácil compreensão, seja pela dificuldade da própria fonte teórica em que se baseia (Lacan), seja pelo estilo não exatamente transparente do autor. $\square$

Eduardo Viveiros de Castro 